\title{
Intermediate-Range Order of Alkali Disilicate Glasses and Its Relation to the Devitrification Mechanism
}

\author{
James G. Longstaffe, ${ }^{\dagger}$ Ulrike Werner-Zwanziger,$^{\dagger}$ Jose F. Schneider,, \\ Marcio L. F. Nascimento, ${ }^{\S}$ Edgar D. Zanotto, ${ }^{\S}$ and Josef W. Zwanziger*, ${ }^{\dagger}$ \\ Department of Chemistry and Institute for Research in Materials, Dalhousie University, Halifax, \\ Nova Scotia, Canada, Departamento de Engenharia de Materiais, Universidade Federal de São Carlos, \\ 13565-905 São Carlos, SP, Brazil, and Instituto de Física de São Carlos, Universidade de São Paulo, \\ 13560-970 São Carlos, SP, Brazil
}

Received: December 4, 2007; In Final Form: January 28, 2008

\begin{abstract}
There are two general mechanisms of devitrification in glass: heterogeneous nucleation of crystals from surfaces and impurities and homogeneous nucleation from the volume. It is thought that structural similarities between glass and crystal at the intermediate-range level influence the mechanism followed; however, there are scarce experimental studies to test this hypothesis. In this paper solid-state nuclear magnetic resonance spectroscopy is used to probe intermediate-range order in sodium and lithium disilicate glasses through measurement of the second moment of the distribution of dipolar couplings. These two glasses undergo heterogeneous and homogeneous nucleation, respectively. The second moments measured for the lithium glass closely follow the trend established by the layered structures of the isochemical crystalline phases, while the same measurements for the sodium glass do not. This observation supports the hypothesis that glasses capable of homogeneous nucleation are structurally more similar to the resulting crystalline phases than those glasses that exhibit only heterogeneous nucleation.
\end{abstract}

\section{Introduction}

One of the major issues in glass science is the origin of the nucleation mechanisms leading to devitrification (uncontrolled crystallization) during cooling of a melt or heating of a glass. Devitrification and crystallization are processes of particular interest to earth scientists concerned with igneous rock formation, ${ }^{1,2}$ chemists studying basic crystallization processes, ${ }^{3-5}$ and technologists interested in the development and applications of glass-ceramics. ${ }^{6-8}$ Glass-ceramics are important composite materials formed by controlled devitrification of glasses in a manner such that properties of the glass and crystal as well as characteristics unique to the final product are included into the new material. This includes thermal, optical, mechanical, and electronic properties among others. When these properties are combined with the processing capabilities of glasses, glassceramics lend themselves to diverse applications such as telescope mirrors, dental crowns, and architectural facades. ${ }^{6}$

Most generally, when held at a temperature at or above the glass transition for some period of time glasses will crystallize from nuclei that form at interfaces, such as container walls and solid impurities. ${ }^{6,9}$ This route to crystal formation is called heterogeneous nucleation. There are, however, a few glass compositions that will also form crystal nuclei from random structural fluctuations throughout the bulk material without the support of such interfaces. This is called homogeneous nucleation, and in this case, the crystalline domains are randomly scattered throughout the volume rather than aligned and radiating inward from the surfaces. It is not clear what distinguishes those

* To whom correspondence should be addressed. Phone: (902) 4941960. E-mail: jzwanzig@dal.ca.

Dalhousie University.

$\doteqdot$ Universidade de São Paulo.

$\S$ Universidade Federal de São Carlos. glasses capable of this special crystallization pathway from those glasses that will only undergo heterogeneous nucleation when heated (for typical laboratory time/size scales) $;{ }^{10}$ however, there is evidence to suggest that the origin lies in the degree of structural similarity between the glass and crystal. ${ }^{5,11,12}$ Specifically, it is hypothesized that those glass compositions that are capable of homogeneous nucleation are structurally more similar to the resulting crystalline phases than those glasses that are only capable of heterogeneous nucleation. ${ }^{10,12}$

Much glass research has focused on understanding short-range order, which describes first-neighbor coordination environments, ${ }^{13-20}$ as well as tetrahedral connectivity in glass. ${ }^{21-24}$ In general, it is found for these features of structural order that glasses are essentially the same as the analogous crystalline phases, regardless of crystal nucleation mechanism. ${ }^{12,25}$ Less work has been directed toward understanding intermediate-range order in glass. The features of this structural regime are less obvious and subtler than those of short-range order and as such are more difficult not only to study but also to define. Intermediate-range order is usually described in terms of microscale phase separations that result in cation clustering or to general topological features such as chains, rings, and layers. ${ }^{13,26,27}$

With regard to intermediate-range structure, several molecular dynamics studies have argued evidence for cation percolation channels. ${ }^{18,27}$ However, experimental evidence of these types of structures is limited. Meyer et al. suggested that prepeaks in neutron scattering data have their origins in these cation clusters. $^{28}$ Gaskell, too, suggested that the so-called low-Q features in scattering data are caused by intermediate-range structure. ${ }^{25}$ There are strong inclinations toward the proposal that similar to short-range order, intermediate-range order in glass is essentially similar to that in crystalline phases. The lack of long-range periodic order in glass, however, means that 

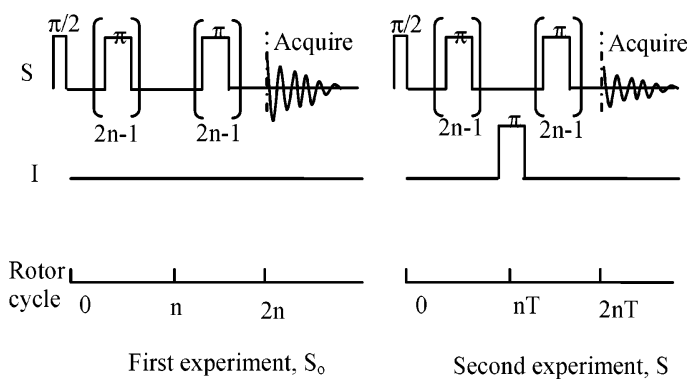

Figure 1. Pulse sequence for REDOR NMR experiments when $I>$ $1 / 2$.

diffraction techniques are inefficient at resolving these features and as such are not necessarily the best methods to elucidate features of intermediate-range order. Solid-state NMR, which does not require long-range order to be effective, has the potential to probe intermediate-range order in glasses. Seminal work in this direction has been completed by Eckert and coworkers, ${ }^{29-37}$ who developed methods to extract heteronuclear dipolar second-moment information from rotational echo double resonance (REDOR) experiments, and by Ratai, ${ }^{38}$ Zwanziger, ${ }^{39}$ and Gee, ${ }^{40}$ who extracted homonuclear dipolar second moments of various glass-modifying species using spin-echo decay experiments.

Dipolar interactions act through space between any pair of nuclei possessing nonzero spin. The van Vleck second moment ${ }^{41,42}$ is the summation of the distribution of dipolar interactions felt at a nucleus from an environment of similar nuclei

$$
M_{2 \mathrm{E}}=E_{\mathrm{L}}\left(\mu_{\mathrm{o}} / 4 \pi\right)^{2} \gamma^{4} \hbar^{2} \Sigma r_{i j}{ }^{-6}
$$

or between completely different nuclei

$$
M_{2}(S-I)=4 / 15\left(\mu_{\mathrm{o}} / 4 \pi\right)^{2} \gamma_{S}^{2} \gamma_{I}^{2} I(I+1) \hbar^{2} \Sigma r_{\mathrm{SI}}{ }^{-6}
$$

In eq $1 M_{2 \mathrm{E}}$ is the homonuclear second moment for quadrupolar nuclei in one of the central transition states ${ }^{38,40}$ and is used in this paper because all nuclei studied using spin-echo decay are spin 3/2. $E_{\mathrm{L}}$ for spin $3 / 2$ nuclei is $0.9562 .{ }^{38}$ For the heteronuclear second moments defined by eq $2, S$ and $I$ refer to the spin angular momentum and identity of the observed and unobserved nucleus, respectively. In both of these equations $\gamma$ is the gyromagnetic ratio. Both heteronuclear and homonuclear second moments are related to the distances between interacting nuclei and thus proposed to be quantitative measures of order up to $15 \AA$.

In this work two compositionally similar glasses, $\mathrm{Na}_{2} \mathrm{O} \cdot 2 \mathrm{SiO}_{2}$ (N2S) and $\mathrm{Li}_{2} \mathrm{O} \cdot 2 \mathrm{SiO}_{2}(\mathrm{~L} 2 \mathrm{~S})$, representing a glass capable only of heterogeneous nucleation (in laboratory size/time scales) and a glass capable of homogeneous nucleation, respectively, are compared. Both of these glasses crystallize isochemically. ${ }^{43-45}$ For the N2S glass ${ }^{23} \mathrm{Na}$ spin-echo decay spectroscopy and ${ }^{29}$ $\mathrm{Si}\left\{{ }^{23} \mathrm{Na}\right\}$ REDOR are used to measure ${ }^{23} \mathrm{Na}$ and ${ }^{29} \mathrm{Si}-{ }^{23} \mathrm{Na}$ second moments. For the L2S glass ${ }^{7} \mathrm{Li}$ spin-echo decay spectroscopy and ${ }^{29} \mathrm{Si}\left\{{ }^{7} \mathrm{Li}\right\}$ REDOR are used to measure ${ }^{7} \mathrm{Li}$ and ${ }^{29} \mathrm{Si}-{ }^{7} \mathrm{Li}$ second moments. These second moments are then used as quantitative measures of intermediate-range order in glass. Comparisons between the second moments of the glasses and their isochemical crystalline phases are used to discuss the possible structural origin of the devitrification mechanism.

\section{Experimental Methods}

All experiments were performed on a Bruker Avance DSX NMR spectrometer operating at a field strength of $9.4 \mathrm{~T}$ and
TABLE 1: Experimental and Calculated Heteronuclear Second Moments $\left({ }^{29} \mathrm{Si}\left\{{ }^{23} \mathrm{Na}\right.\right.$ or $\left.\left.{ }^{7} \mathrm{Li}\right\}\right)$ for Selected Compounds

\begin{tabular}{lcc} 
compound & $\begin{array}{c}\text { calculated } \\
M_{2} / \times 10^{6} \mathrm{rad}^{2} \mathrm{~s}^{-2}(\mathrm{ref})\end{array}$ & $\begin{array}{c}\text { experimental } \\
M_{2 /} \times 10^{6} \mathrm{rad}^{2} \mathrm{~s}^{-2}\end{array}$ \\
\hline Sodalite & $5.44(54)$ & 5.16 \\
$\alpha-\mathrm{Na}_{2} \mathrm{Si}_{2} \mathrm{O}_{5}$ & $7.44(55)$ & 7.15 \\
$\mathrm{Na}_{2} \mathrm{SiF}_{6}$ & $7.62(56)$ & 7.32 \\
$\mathrm{Li}_{2} \mathrm{SiO}_{3}$ & $43(53)$ & 44
\end{tabular}

using a $4 \mathrm{~mm}$ HXY probe. The double-resonance inserts required for the ${ }^{29} \mathrm{Si}\left\{{ }^{23} \mathrm{Na}\right\}$ and ${ }^{29} \mathrm{Si}\left\{{ }^{7} \mathrm{Li}\right\}$ experiments were homemade.

For the REDOR experiments magic angle spinning rates varied from 4 to $12 \mathrm{kHz}$. The pulse sequence shown in Figure $1^{46,47}$ was employed, utilizing a single $\pi$ pulse on the spin $3 / 2$ nuclei $\left({ }^{23} \mathrm{Na}\right.$ and $\left.{ }^{7} \mathrm{Li}\right)$ rather than a $\pi$ train so as to minimize the consequences of nonselective $\pi$ pulses. In all REDOR experiments the observed nucleus' pulse lengths were optimized by maximizing the signal from the first half of a REDOR experiment. The $\pi$ pulse on the unobserved nucleus was optimized by minimizing the signal of the second half of the REDOR experiment. For the room-temperature ${ }^{23} \mathrm{Na} /{ }^{29} \mathrm{Si}$ experiments ${ }^{29} \mathrm{Si} \pi / 2$ pulses were typically between 7.6 and 8.0 $\mu$ s and $\pi$ pulses 15 and $16 \mu \mathrm{s} .{ }^{23} \mathrm{Na} \pi$ pulse lengths varied from 8.5 to $27 \mu$ s at a power level of $16.6 \mathrm{kHz}$. The $\mathrm{Na}_{2} \mathrm{O} \cdot 2 \mathrm{SiO}_{2}$ glass experiments were performed at $183 \mathrm{~K}$ and ${ }^{29} \mathrm{Si} \pi / 2$ and $\pi$ pulse lengths were 7.0 and $14.0 \mu \mathrm{s}$, respectively, while the ${ }^{23}$ $\mathrm{Na} \pi$ pulse was $10 \mu \mathrm{s}$ at a power of $21.5 \mathrm{kHz}$. For the ${ }^{7} \mathrm{Li} /{ }^{29} \mathrm{Si}$ experiments ${ }^{29} \mathrm{Si} \pi / 2$ and $\pi$ pulses were 11.75 and $23.5 \mu \mathrm{s}$, respectively. ${ }^{7} \mathrm{Li} \pi$ pulses were between 18 and $23 \mu$ s at a power of $21.7 \mathrm{kHz}$. Typical recycle delays varied from 5 to $45 \mathrm{~s}$. In most experiments -200 scans were needed to achieve acceptable signal-to-noise.

For the ${ }^{23} \mathrm{Na}$ and ${ }^{7} \mathrm{Li}$ spin-echo experiments a simple Hahn echo sequence was used under static conditions. To minimize the effects of magnetic field inhomogeneity only the center third of the rotor was filled with sample. Experiments were performed at room temperature except for the $\mathrm{Na}_{2} \mathrm{O} \cdot 2 \mathrm{SiO}_{2}$ glass, which was also performed at $200 \pm 10 \mathrm{~K}$. For the ${ }^{23} \mathrm{Na}$ experiments pulse powers were $8.7 \mathrm{kHz}$ so as to achieve selective excitation of the central transition. At this power level $\pi / 2$ pulses were optimized to be between 11 and $14.5 \mu$ s and $\pi$ pulses 22 and $29 \mu \mathrm{s}$. Recycle delays used were between 1 and $60 \mathrm{~s}$. For the ${ }^{7} \mathrm{Li}$ experiments pulse powers of 4.4 and $3.6 \mathrm{kHz}$ were used to achieve selective excitation of the central transition for $\mathrm{Li}_{2} \mathrm{SiO}_{3}$ and $\mathrm{Li}_{2} \mathrm{O} \cdot 2 \mathrm{SiO}_{2}$ glass, respectively. The $\pi / 2$ and $\pi$ pulse lengths at these powers were 20 and $40 \mu$ s for $\mathrm{Li}_{2} \mathrm{SiO}_{3}$ and 21.5 and 43 $\mu$ s for the $\mathrm{Li}_{2} \mathrm{O} \cdot 2 \mathrm{SiO}_{2}$ glass, respectively. Recycle delays were typically on the order of $5 \mathrm{~s}$.

The N2S and L2S glasses were prepared by melting and then quenching stoichiometric mixtures of $\mathrm{Na}_{2} \mathrm{O}$ or $\mathrm{Li}_{2} \mathrm{O}$ and $\mathrm{SiO}_{2}$ along with trace amounts of paramagnetic $\mathrm{Mn}^{2+}$ to assist with ${ }^{29} \mathrm{Si} T_{1}$ relaxation. It is generally accepted that trace levels of such dopants do not affect the structure of the glass. ${ }^{48} \alpha-\mathrm{Na}_{2}-$ $\mathrm{Si}_{2} \mathrm{O}_{5}$ was prepared by devitrification of a sample of $\mathrm{N} 2 \mathrm{~S}$ glass. $\mathrm{Li}_{2} \mathrm{SiO}_{3}$ and $\mathrm{Na}_{2} \mathrm{SiO}_{3}$ were prepared by fusing stoichiometric quantities of $\mathrm{Na}_{2} \mathrm{O}$ or $\mathrm{Li}_{2} \mathrm{O}$ and $\mathrm{SiO}_{2}$ in a melt and then slow cooling until crystallization. Sodalite was purchased from a craft store in Halifax; the authenticity of the sample was verified by the ${ }^{23} \mathrm{Na}$ chemical shift. ${ }^{49} \mathrm{Na}_{2} \mathrm{SiF}_{6}$ was used as purchased from Aldrich.

\section{Results}

Measurement of Heteronuclear Second Moments Using REDOR. It has been shown by others that the initial part of a 

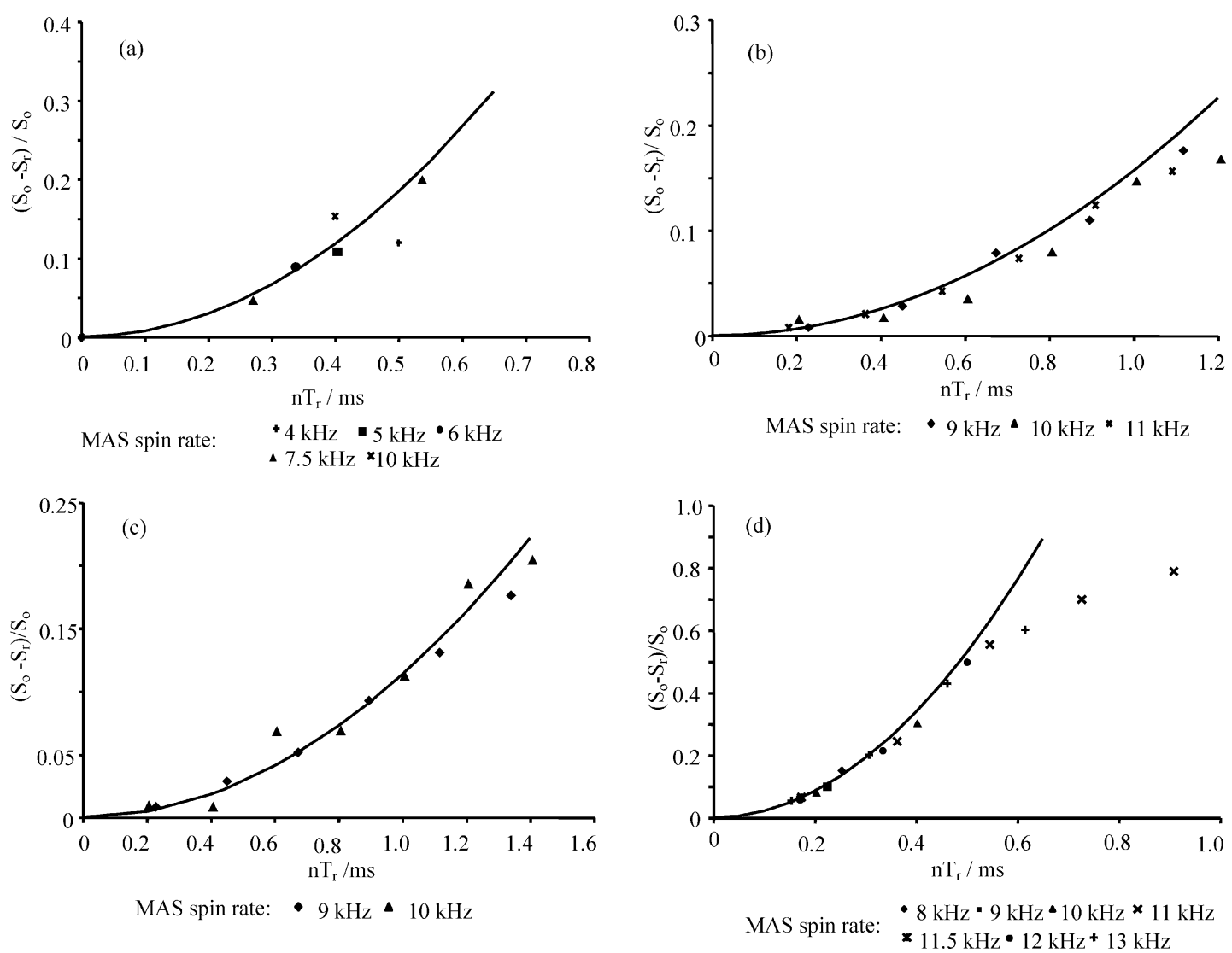

Figure 2. Experimental REDOR data: (a) ${ }^{29} \mathrm{Si}\left\{{ }^{23} \mathrm{Na}\right\}$ REDOR of Sodalite $\left(C_{\mathrm{Q}}=0 \mathrm{kHz}, f_{1}=1\right)$; (b) ${ }^{29} \mathrm{Si}\left\{{ }^{23} \mathrm{Na} \mathrm{REDOR}_{\mathrm{O}}\right.$ of $\mathrm{Na}_{2} \mathrm{SiF} \mathrm{F}_{6}\left(C_{\mathrm{Q}}=0.80\right.$ $\left.\mathrm{MHz}, f_{1}=0.065\right)$; (c) ${ }^{29} \mathrm{Si}\left\{{ }^{23} \mathrm{Na}\right\}$ REDOR of $\alpha-\mathrm{Na}_{2} \mathrm{Si}_{2} \mathrm{O}_{5}\left(C_{\mathrm{Q}}=1.77 \mathrm{MHz}, f_{1}=0.019\right)$; (d) ${ }^{29} \mathrm{Si}\left\{{ }^{7} \mathrm{Li}\right\} \mathrm{REDOR}$ of $\mathrm{Li}_{2} \mathrm{SiO}_{3}\left(C_{\mathrm{Q}}=200 \mathrm{kHz}, f_{1}=\right.$ 0.684). $M_{2}$ for each graph is determined by fitting the data to eq 3 , producing the parabolic curves shown.

REDOR dephasing curve, where the REDOR fraction, $\left(S_{0}-\right.$ $S) / S_{\text {o }}$, is less than 0.2 , can be fit to a parabolic approximation in which the heteronuclear dipolar second moment, $M_{2}$, is the sole unknown. ${ }^{50}$ The rotor period, $T_{\mathrm{r}}$, is a controlled variable used to modulate the extant of dipolar dephasing. Difficulties emerge, however, when at least one of the nuclei is quadrupolar in that neither selective excitation of the central transition nor excitation of the full spectrum is always possible. Using the methods developed by Eckert, a phenomenological fitting factor, $f_{1}$, can be introduced into the parabolic fit to account for the degree of satellite excitation of the quadrupolar nuclei ${ }^{30,51}$

$$
\left(S_{\mathrm{o}}-S_{\mathrm{r}}\right) / S_{\mathrm{o}}=1 / 15 \pi^{2}\left(18+2 f_{1}\right)\left(n T_{\mathrm{r}}\right)^{2} M_{2}
$$

This $f_{1}$ value can be determined by running a SIMPSON simulation with the exact operating conditions, including $C_{\mathrm{Q}}$ and $\eta$, of the real experiment and a user-defined value for the second moment. ${ }^{31,52}$ When $C_{\mathrm{Q}}$ is large and there is selective excitation of the central transition, $f_{1}$ is 0 ; when $C_{\mathrm{Q}}$ is negligibly small and there is excitation of the full spectrum, $f_{1}$ is 1 . This technique has been shown to be very effective for ${ }^{29} \mathrm{Si}\left\{{ }^{7} \mathrm{Li}\right\}$ REDOR experiments; ${ }^{37}$ however, thus far reported ${ }^{29} \mathrm{Si}\left\{{ }^{23} \mathrm{Na}\right\}$ experiments have only been qualitative. ${ }^{35}$ To verify the accuracy of the ${ }^{29} \mathrm{Si}\left\{{ }^{7} \mathrm{Li}\right\}$ REDOR experiment, the $M_{2}$ of a crystalline sample of $\mathrm{Li}_{2} \mathrm{SiO}_{3}{ }^{53}$ was determined. The ${ }^{29} \mathrm{Si}\left\{{ }^{23} \mathrm{Na}\right\}$ experiment was verified on a sample of the mineral sodalite, ${ }^{54} \alpha-\mathrm{Na}_{2} \mathrm{Si}_{2} \mathrm{O}_{5},{ }^{55}$ and $\mathrm{Na}_{2} \mathrm{SiF}_{6}{ }^{56}$ Second moments of the crystalline phases were calculated by computing a pair-distribution function at the highest resolution from 0 to $15 \AA$ such that a value for each possible distance under $15 \AA$ is given. The crystalline second moments are then determined using these distances and eqs 1 and 2. Table 1 and Figure 2 summarize all of the REDOR experiments on crystalline compounds; clearly there is excellent agreement between experimental and theoretical second moments over a wide range of quadrupolar couplings.

$\mathrm{Na}_{2} \mathrm{O} \cdot 2 \mathrm{SiO}_{2}$ Glass. The REDOR curve of the sodium disilicate glass is shown in Figure 3a. For this material the ${ }^{23} \mathrm{Na}$ relaxation is extraordinarily fast and the signal decays completely within $100 \mu \mathrm{s}$. This fast relaxation has been attributed to increased sodium mobility in sodium silicate glasses with higher sodium concentrations, ${ }^{35,40}$ and several authors have proposed the existence of ion percolation channels in the structure of sodium disilicate glass to account for this increased mobility. ${ }^{28,57-59}$ Because of the quick ${ }^{23} \mathrm{Na}$ signal decay, a REDOR experiment is impossible under ambient conditions, and in order to quench the sodium mobility the ${ }^{29} \mathrm{Si}\left\{{ }^{23} \mathrm{Na}\right\}$ REDOR experiment for the N2S glass was performed at 183 $\pm 10 \mathrm{~K}$. It is not expected that the low temperatures will alter the observed ${ }^{23} \mathrm{Na}-{ }^{29} \mathrm{Si}$ interactions within the error of the $M_{2}$ measurement.

Sodium nuclei in the glass exist with a wide distribution of second-order quadrupolar coupling constants; however, a modal value for the glass can be estimated by fitting the powder line shape of a MAS cross-section of the ${ }^{23} \mathrm{Na}$ MQMAS spectrum, shown in Figure $4 \mathrm{a}$ and $\mathrm{b}$, at its maximum intensity. The resulting $C_{\mathrm{Q}}$ for this glass is $2.9 \pm 0.2 \mathrm{MHz}$ with a $\eta$ value of 0.2. This $C_{\mathrm{Q}}$ is greater than those reported for the various crystalline $\mathrm{Na}_{2} \mathrm{Si}_{2} \mathrm{O}_{5}$; however, both of the sodium sites in the $\beta$ crystalline phase and one of the sites in the $\delta$ crystalline phase have $C_{\mathrm{Q}}$ values around $2.5 \mathrm{MHz}$, suggesting that the value estimated for the glass is not unreasonable. For this glass the $f_{1}$ fitting factor is 0 , and a ${ }^{29} \mathrm{Si}\left\{{ }^{23} \mathrm{Na}\right\} \mathrm{M}_{2}$ value of $8.8 \times 10^{6} \mathrm{rad}^{2}$ 

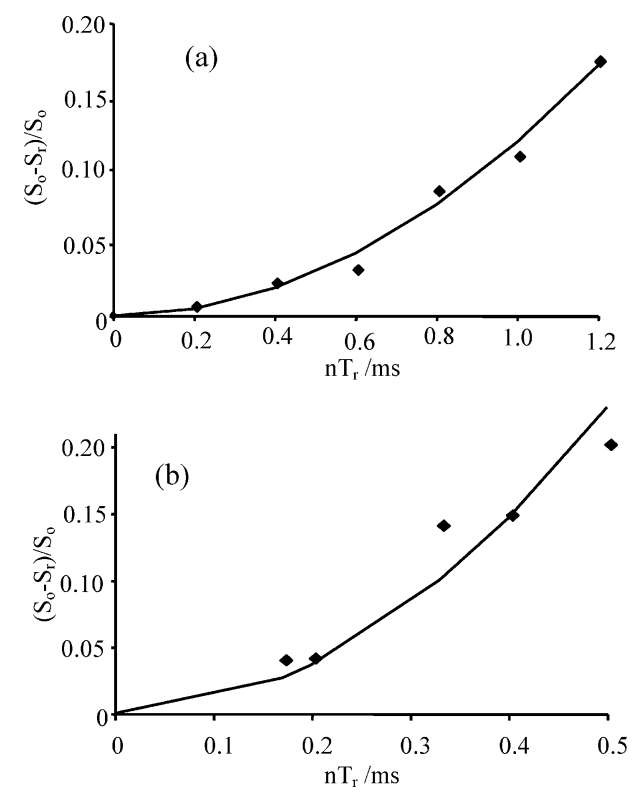

Figure 3. Experimental REDOR curves from the two alkali disilicate glasses: (a) ${ }^{29} \mathrm{Si}\left\{{ }^{23} \mathrm{Na}\right\}$ REDOR data for the $\mathrm{Na}_{2} \mathrm{O} \cdot 2 \mathrm{SiO}_{2}$ glass $\left(C_{\mathrm{Q}}=\right.$ $2.9 \mathrm{MHz}, \eta=0.2, f_{1}=0.0$ ); (b) ${ }^{29} \mathrm{Si}\left\{{ }^{7} \mathrm{Li}\right\}$ REDOR data for the $\mathrm{Li}_{2} \mathrm{O} \cdot$ $2 \mathrm{SiO}_{2}$ glass $\left(C_{\mathrm{Q}}=0.16 \mathrm{MHz}, \eta=1.0, f_{1}=0.3168\right) . M_{2}$ for each graph is determined by fitting the data to eq 3 , producing the parabolic curves shown.

$\mathrm{s}^{-2}$ was determined for the glass with an estimated error of $\pm 10 \%$. Separation of the total $M_{2}$ into the contributions from $Q^{2}, Q^{3}$, and $Q^{4}$ silicon species is not possible because of the very low concentrations of the $Q^{2}$ and $Q^{4}$ components.

$\mathrm{Li}_{2} \mathrm{O} \cdot 2 \mathrm{SiO}_{2}$ Glass. The ${ }^{29} \mathrm{Si}\left\{{ }^{7} \mathrm{Li}\right\}$ REDOR plot is shown in Figure $3 \mathrm{~b}$. A $C_{\mathrm{Q}}$ of $160 \pm 20 \mathrm{kHz}$ with a $\eta$ value of 1.0 was determined by fitting the ${ }^{7} \mathrm{Li}$ MAS pattern of the glass shown in Figure 4c. An $f_{1}$ fitting factor of 0.3168 was used to determine a $M_{2}$ of $17.6 \times 10^{6} \mathrm{rad}^{2} \mathrm{~s}^{-2}$ for this sample with an estimated error of $\pm 10 \%$. Similar to the sodium disilicate glass, separation of the total $M_{2}$ into the contributions from $Q^{2}, Q^{3}$, and $Q^{4}$ was not possible. Voigt et al. ${ }^{37}$ report a $M_{2}$ of $13.5 \times 10^{6} \mathrm{rad}^{2} \mathrm{~s}^{-2}$ of the $Q^{3}$ species alone for this glass composition. While this $M_{2}$ value is lower than the value found here for the whole glass by around $5 \%$, the two results are qualitatively of similar magnitude. It is expected that higher charged silicon species will be in closer spatial proximity to lithium cations than lower charged species, meaning that the expected $M_{2}$ 's should follow the sequence of $Q^{2}>Q^{3}>Q^{4}$. Because $Q^{3}$ is the dominant species in this glass the total $M_{2}$ should be similar Voigt's $Q^{3}$ measurement but will depend also upon the exact strengths of the second moment for the $Q^{2}$ and $Q^{4}$ species.

Measurement of Homonuclear Second Moments by SpinEcho Decay Spectroscopy. It has been shown that static spinecho decay experiments are effective at measuring the homonuclear second moment of both spin $1 / 2$ and half integer quadrupolar nuclei. ${ }^{38-40,59,60}$ To achieve good quantitative measurements for quadrupolar nuclei, however, it is necessary to selectively excite the central transition. This means that for nuclei where the quadrupolar coupling is weak, such as for ${ }^{7}$ $\mathrm{Li}$, very long pulse lengths are a necessity. Unfortunately, this means that while the technique is well developed for nuclei such as ${ }^{23} \mathrm{Na}$, very little successful work has been reported for ${ }^{7} \mathrm{Li}$. Puls et al. suggested using ${ }^{6} \mathrm{Li} /{ }^{7} \mathrm{Li}$ double-resonance experiments similar information. ${ }^{61}$

In general, for a spin-echo decay experiment a simple Hahn echo is acquired over a series of experiments in which the delay
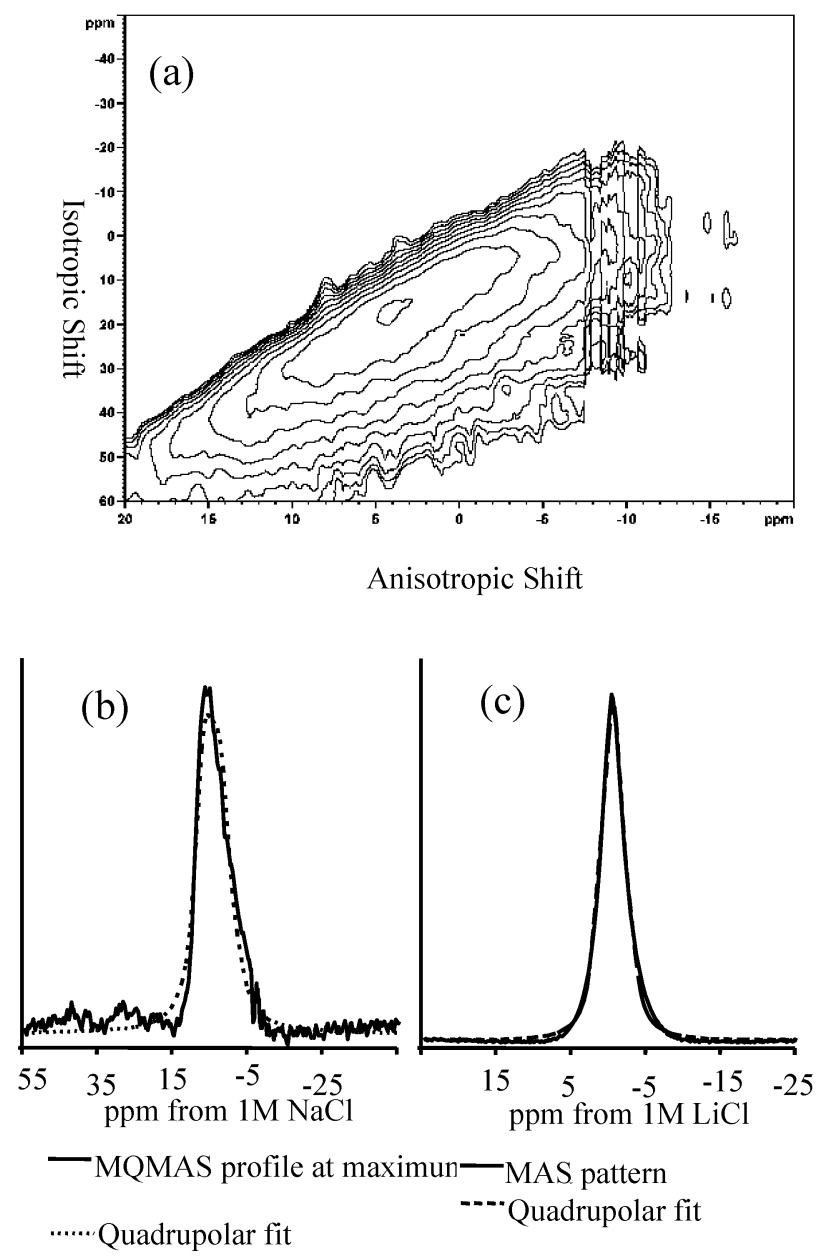

Figure 4. (a) ${ }^{23} \mathrm{Na} \mathrm{MQMAS}$ of the $\mathrm{Na}_{2} \mathrm{O} \cdot 2 \mathrm{SiO}_{2}$ glass. (b) Profile of the ${ }^{23} \mathrm{Na}$ MQMAS spectrum of $\mathrm{Na}_{2} \mathrm{O} \cdot 2 \mathrm{SiO}_{2}$ glass at its maximum and the quadrupolar fit. (c) The quadrupolar fit to a ${ }^{7} \mathrm{Li}$ MAS spectrum of the $\mathrm{Li}_{2} \mathrm{O} \cdot 2 \mathrm{SiO}_{2}$ glass.

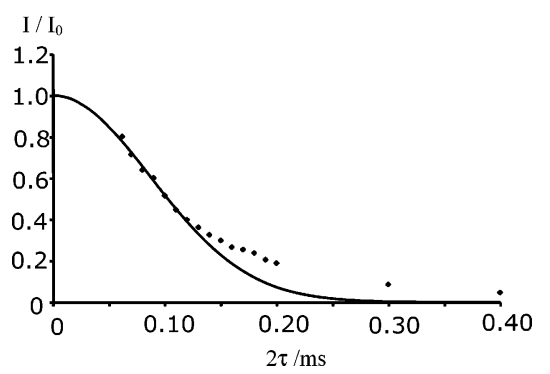

Figure 5. ${ }^{7} \mathrm{Li}$ spin-echo decay curve of $\mathrm{Li}_{2} \mathrm{SiO}_{3} . M_{2 \mathrm{E}}$ is determined by fitting the data to eq 4 , producing the exponential decay curve shown.

before the $\pi$ refocusing pulse, $\tau$, is treated as a variable. A plot of $I / I_{0}$, where $I_{0}$ is the extrapolated signal intensity at $\tau=0$, is an exponential function of $2 \tau$ and $\mathrm{M}_{2 \mathrm{E}}$

$$
I(2 \tau) / I_{0}=\exp \left[-\left(M_{2 \mathrm{E}} / 2\right)(2 \tau)^{2}\right]
$$

$M_{2 \mathrm{E}}$ is extracted by fitting the initial decay of the curve, generally $2 \tau \leq 200$ us, where signal loss is dominated by homonuclear dipolar coupling-induced spin-lattice relaxation. For $\mathrm{Na}_{2} \mathrm{SiO}_{3}{ }^{62}$ and $\mathrm{Na}_{2} \mathrm{SO}_{4}{ }^{63}$ the measured and calculated second moments agree very well, as shown in Table 2. Likewise, there is good agreement between the calculated and experimental ${ }^{7}$ $\mathrm{Li}$ second moment for $\mathrm{Li}_{2} \mathrm{SiO}_{3},{ }^{53}$ for which the decay curve is shown in Figure 5. In general, the difference between the expected and observed values is less than $10 \%$. 

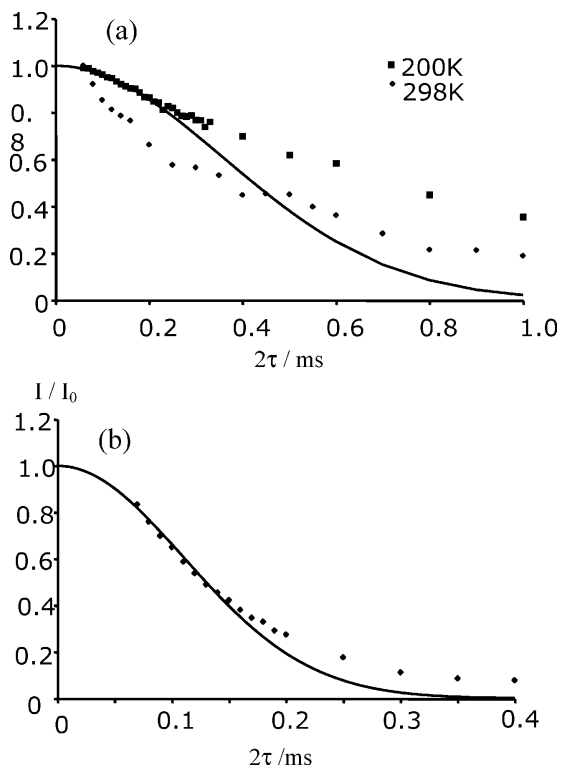

Figure 6. (a) ${ }^{23} \mathrm{Na}$ spin-echo decay of $\mathrm{Na}_{2} \mathrm{O} \cdot 2 \mathrm{SiO}_{2}$ glass at room temperature and $200 \mathrm{~K}$. (b) ${ }^{7} \mathrm{Li}$ spin-echo decay of the $\mathrm{Li}_{2} \mathrm{O} \cdot 2 \mathrm{SiO}_{2}$ glass. $M_{2 \mathrm{E}}$ is determined by fitting the data to eq 4 , producing the exponential decay curves shown.

TABLE 2: Measured and Calculated Homonuclear Second Moments Measured Using Spin-Echo Decay Spectroscopy, Including Those Measurements Reported by Other Authors Where Available

\begin{tabular}{ccc}
\hline & $\begin{array}{c}\text { calculated } \\
\text { compound }\end{array}$ & $\begin{array}{c}\text { experimental } \\
M_{2 \mathrm{E}} / 10^{6} \mathrm{rad}^{2} \mathrm{~s}^{-2}(\mathrm{ref})\end{array}$ \\
\hline $\mathrm{Na}_{2} \mathrm{SiO}_{3}$ & $19.5(62)$ & 22.9 \\
& & $14.6(40)$ \\
$\mathrm{Na}_{2} \mathrm{SO}_{4}$ & $12.7(63)$ & 11.8 \\
& & $12.8(39)$ \\
$\mathrm{Li}_{2} \mathrm{SiO}_{3}$ & $134(53)$ & $11.5(40)$
\end{tabular}

Similar to REDOR, it has been noted that this experiment will not work for many sodium silicate glasses at room temperature as low temperatures are required to quench ion mobility. ${ }^{39,40}$ Figure 6 a shows ${ }^{23} \mathrm{Na}$ spin-echo results of the $\mathrm{Na}_{2} \mathrm{O} \cdot 2 \mathrm{SiO}_{2}$ glass at room temperature, $298 \mathrm{~K}$, and low temperature, $200 \mathrm{~K}$. At $200 \mathrm{~K}$ the curve matches the exponential decay expected, allowing for a calculation of the homonuclear $M_{2 \mathrm{E}}$. The measured second moment, $7.7 \times 10^{6} \mathrm{rad}^{2} \mathrm{~s}^{-2}$, is in agreement with the trend reported by Gee et al. for a series of $\left(\mathrm{Na}_{2} \mathrm{O}\right)_{x}\left(\mathrm{SiO}_{2}\right)_{x-1}$ glasses. ${ }^{40}$ These authors report homonuclear ${ }^{23} \mathrm{Na} M_{2 \mathrm{E}}$ values increasing from 4.1 to $11.6 \times 10^{6} \mathrm{rad}^{2} \mathrm{~s}^{-2}$ as $x$ increases from 0.28 to 0.50 .

For the $\mathrm{Li}_{2} \mathrm{O} \cdot 2 \mathrm{SiO}_{2}$ glass decay curve, shown in Figure $6 \mathrm{~b}$, the ${ }^{7} \mathrm{Li}$ homonuclear $M_{2 \mathrm{E}}$ was estimated to be approximately $83.2 \times 10^{6} \mathrm{rad}^{2} \mathrm{~s}^{-2}$. The ${ }^{7} \mathrm{Li}$ spin-echo decay curve observed at room temperature is identical to that observed at $200 \mathrm{~K}$ (not shown), verifying that ion mobility does not affect the measurement. Owing to the fact that data for the initial part of the curve overlaps with the spectrometer dead time and therefore is not observable, the ${ }^{7} \mathrm{Li} M_{2 \mathrm{E}}$ measurement is not as reliable as the ${ }^{23} \mathrm{Na}$ measurement. While there are no similar measurements to which the $M_{2 \mathrm{E}}$ can be compared, qualitatively it is of similar magnitude to the $M_{2 \mathrm{E}}$ observed for crystalline $\mathrm{Li}_{2} \mathrm{SiO}_{3}$.

\section{Discussion}

A second moment can be used to infer structure in glass through comparison of values expected from a model to those observed experimentally. Rather than comparing glass structure
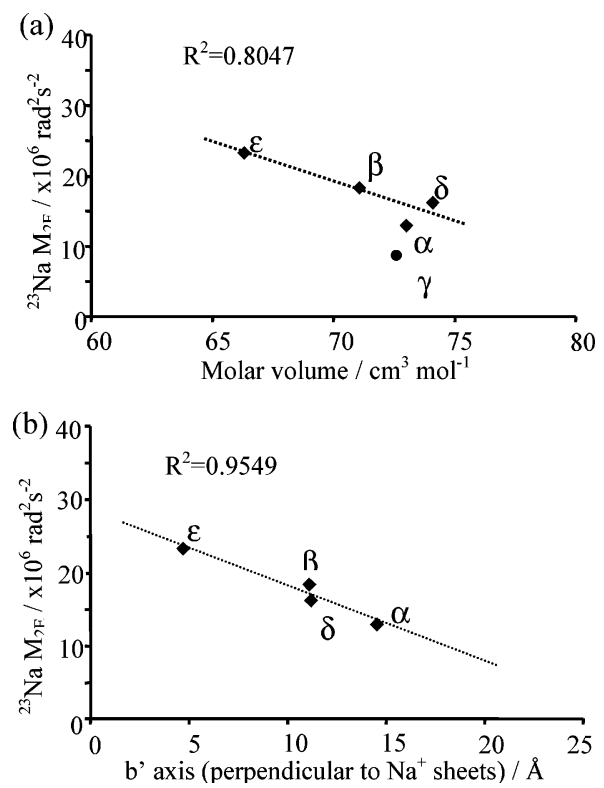

Figure 7. (a) Comparison of the calculated ${ }^{23} \mathrm{Na}$ homonuclear $M_{2 \mathrm{E}}$ of each crystalline $\mathrm{Na}_{2} \mathrm{Si}_{2} \mathrm{O}_{5}$ phase with the molar volume. (b) Comparison of the calculated $M_{2 \mathrm{E}}$ with the $b^{\prime}$ axis perpendicular to the $a b$ plane for layered $\mathrm{Na}_{2} \mathrm{Si}_{2} \mathrm{O}_{5}$ phases. A line of the best fit for each data set is shown along with the corresponding $R^{2}$ factor (the fit in Figure 7a excludes the $\gamma$ data point).

$\alpha$

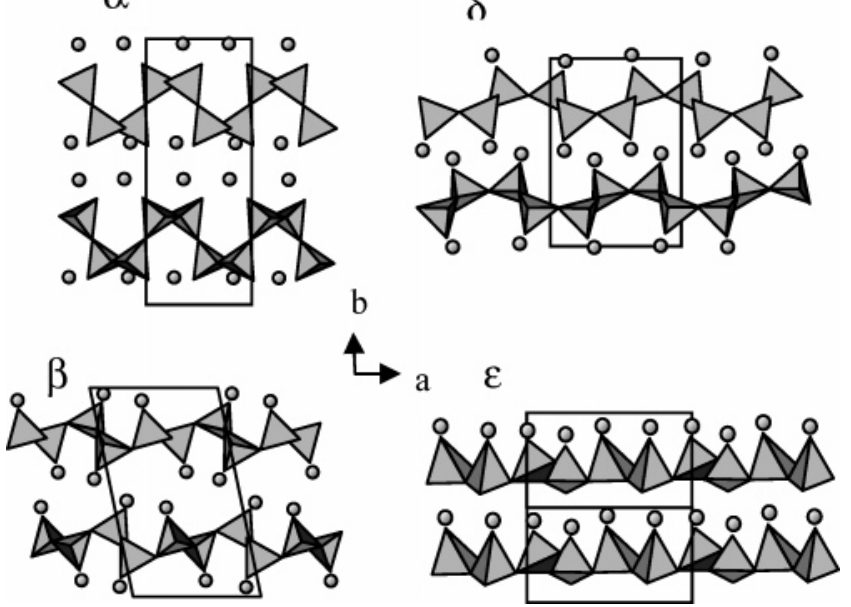

Figure 8. Profiles of the four layered $\mathrm{Na}_{2} \mathrm{Si}_{2} \mathrm{O}_{5}$ phases looking along the $c$ axis. ${ }^{70}$

to models developed using interatomic potentials starting from completely unrelated structures such as $\mathrm{NaCl}$ and $\mathrm{Na}_{2} \mathrm{O}$, as done before, ${ }^{27,28,51,57,64,65}$ it is suggested here that the best models to compare experimental glass structure data to are those of the corresponding isochemical crystalline phases or at least those phases that form readily upon devitrification. This is the best method to understand the essential structural character of glass extending beyond the reach of interatomic potentials. The approach taken here will be similar to the recent attempt by Gaskell to elucidate the structural origins of low- $Q$ structure in neutron scattering data by comparing glass data to that of isochemical crystalline phases. ${ }^{25}$ Similar to how the essential bonding and coordination in silicate glasses is the same as that in crystalline silicates, Gaskell proposes that the essential character of intermediate-range structure of silicate glasses may be similar to that in crystalline silicates. By 'essential character' Gaskell is referring to the essence of how atoms are distributed throughout the material, for example, layering, clustering, or a more homogeneous dispersal. Seemingly, the contrary argument 
TABLE 3: Molar Volumes with Calculated and Measured Hetero- and Homonuclear Dipolar Second Moments for Alkali Disilicate Crystalline and Glassy Phases

\begin{tabular}{|c|c|c|c|c|c|}
\hline phase & molar volume $/ \mathrm{cm}^{3} \mathrm{~mol}^{-1}$ & $b^{\prime}$ axis/Å & $M_{2} / \times 10^{6} \mathrm{rad}^{2} \mathrm{~s}^{-2}$ & $M_{2 \mathrm{E}} / \times 10^{6} \mathrm{rad}^{2} \mathrm{~s}^{-2}$ & structure or density reference \\
\hline$c-\mathrm{Li}_{2} \mathrm{Si}_{2} \mathrm{O}_{5}$ & 62.9 & NA & 22.2 & 98.4 & 66 \\
\hline$m-\mathrm{Li}_{2} \mathrm{Si}_{2} \mathrm{O}_{5}$ & 61.9 & NA & 23.5 & 107 & 67 \\
\hline $\mathrm{L} 2 \mathrm{~S}$ glass & 66.0 & NA & $17.6 \pm 1.8$ & $83.2 \pm 8.3$ & 76 \\
\hline$\alpha-\mathrm{Na}_{2} \mathrm{Si}_{2} \mathrm{O}_{5}$ & 72.9 & 15.42 & 7.44 & 13.3 & 55 \\
\hline$\beta-\mathrm{Na}_{2} \mathrm{Si}_{2} \mathrm{O}_{5}$ & 71.0 & 11.95 & 8.16 & 18.7 & 69 \\
\hline$\delta-\mathrm{Na}_{2} \mathrm{Si}_{2} \mathrm{O}_{5}$ & 74.0 & 12.08 & 7.40 & 16.6 & 70 \\
\hline$\epsilon-\mathrm{Na}_{2} \mathrm{Si}_{2} \mathrm{O}_{5}$ & 66.2 & 5.58 & 9.14 & 23.6 & 72 \\
\hline$\gamma-\mathrm{Na}_{2} \mathrm{Si}_{2} \mathrm{O}_{5}$ & 73.5 & NA & 7.19 & 9.64 & 73 \\
\hline N2S glass & 72.9 & NA & $8.8 \pm 0.9$ & $7.7 \pm 0.8$ & 76 \\
\hline
\end{tabular}

to this is that the glass-forming process suggests a structural motif that is essentially different from that of the crystalline phases. These two arguments are not necessarily contradictory, especially if the hypothesis of this paper is considered: lithium disilicate glass has a structure essentially similar to that of the crystalline phases, whereas the structure of sodium disilicate glass is less similar, thus explaining why the L2S glasses resistance to homogeneous nucleation is less than that of the N2S glass.

While the comparisons between the low- $Q$ features in neutron scattering data of glassy and crystalline alkali disilicates were inconclusive, owing to the lack of long-range translational order in the glasses, NMR is well suited to the study of amorphous materials, particularly for its ability to measure dipolar second moments with increasing accuracy. The method for comparing crystalline and amorphous second moments is less obvious than for scattering data because a second moment, while representative of average spatial distributions, is manifested only as a single number with units irrelevant to spatial geometry. At least one other work has attempted to correlate ${ }^{23} \mathrm{Na}$ homonuclear second moments of glass to structural models, including some crystalline structures. ${ }^{27}$ That work, however, considered only two of the several $\mathrm{Na}_{2} \mathrm{Si}_{2} \mathrm{O}_{5}$ crystalline phases and did not discuss the structural origins of the crystalline second moments, focusing instead the molar content of sodium. The approach taken here will be more thorough with regard to the structural implications of second-moment measurements.

Both the N2S and L2S glasses crystallize isochemically, meaning that the only stable phases formed by devitrification have $\mathrm{M}_{2} \mathrm{Si}_{2} \mathrm{O}_{5}$ stoichiometry. The L2S glass has been observed to form metastable $\mathrm{Li}_{2} \mathrm{SiO}_{3}$ homogeneously; ${ }^{45}$ however, this phases presence is independent of the homogeneous nucleation of $\mathrm{Li}_{2} \mathrm{Si}_{2} \mathrm{O}_{5}$ and only forms in very small volume fractions compared to the stoichiometric $\mathrm{Li}_{2} \mathrm{Si}_{2} \mathrm{O}_{5}$. A metastable $\mathrm{Li}_{2} \mathrm{Si}_{2} \mathrm{O}_{5}$ has been observed by DSC; ${ }^{45}$ however, crystal structures have only been resolved for the single stable phase. ${ }^{66}$ Another metastable $\mathrm{Li}_{2} \mathrm{Si}_{2} \mathrm{O}_{5}$ phase has been prepared by ion exchange with $\alpha-\mathrm{Na}_{2} \mathrm{Si}_{2} \mathrm{O}_{5}$ for which a crystal structure is known. ${ }^{67}$ Both the stable, $c$, and metastable, $m, \mathrm{Li}_{2} \mathrm{Si}_{2} \mathrm{O}_{5}$ phases are composed entirely of $Q^{3}$ silicon and layered. The crystalline $\mathrm{Na}_{2} \mathrm{Si}_{2} \mathrm{O}_{5}$ phases are more diverse, with at least five different phases having resolved crystal structures. Four of these, $\alpha, \beta, \delta$, and $\gamma$, are readily formed by devitrification of the N2S glass; $43,44,55,68,69$ however, of these only the $\alpha$ phase is stable, while the $\delta$ and $\gamma$ phases are highly metastable. ${ }^{70,71}$ One other phase with known structure, $\epsilon$, is formed only under very high pressures. ${ }^{72}$ All five of these phases are composed entirely of $Q^{3}$ silicon, and all but $\gamma$ have a layered topology. The structure of the $\gamma$ phase is similar to $\mathrm{K}_{2} \mathrm{Si}_{2} \mathrm{O}_{5}$ and can be described as a network topology similar to cristobalite with $20 \%$ of the silicon removed. ${ }^{73}$

For crystalline silicates there are three primary structural factors that control the strength of both the homo- and the heteronuclear dipole second moments: composition, density, and topology ${ }^{74}$ For layered silicates, topology can be split into three general secondary factors: intralayer distances between alkali cations, interlayer distances between alkali cations, and interlayer interactions between alkali cations and silicate structures.

(1) Composition. Second moments are representative of bulk dipolar interactions. For example, when the number density of the unobserved nucleus is decreased in the material, the strength of the $M_{2}$ measured at the observed nucleus diminishes.

(2) Density. When more particles are confined in smaller spaces the average internuclear distances must decrease, resulting in an increase in the second moment. Density is best represented as molar volume $\left(\mathrm{cm}^{3} \mathrm{~mol}^{-1}\right)$ in order that composition may also be taken into consideration.

(3) Topology. Crystalline silicates exist in a diverse selection of topologies, including 3D networks, infinite sheets, infinite chains, interconnected rings, and small discrete ions. ${ }^{75}$ Topology is the structural manifestation of how the atoms are ordered at the intermediate range, and therefore, it is proposed here that second-moment measurements should reflect these differences to some degree. For example, all other parameters being the same, a layered structure would be expected to give a different value for a second moment than a network structure because layering produces a fluctuation in density at the atomic level that disrupts the homogeneous distribution of cations. Consider the plot of calculated ${ }^{23} \mathrm{Na}$ homonuclear $M_{2 \mathrm{E}}$ as a function of molar volume for the five major $\mathrm{Na}_{2} \mathrm{Si}_{2} \mathrm{O}_{5}$ crystalline phases shown in Figure 7a. There is a very good linear correlation among three of the four layered phases ( $\alpha$ is the exception as will be explained below); the $\gamma$ phase is a network silicate, however, and its value lies considerably below the linear trend observed for the layered structures.

The origin of the relationship between the topology of crystalline silicates and second moments is described further by two secondary factors for the homonuclear $M_{2 \mathrm{E}}$, which will explain the anomalously low $\alpha$-phase second moment, and one secondary factor for the heteronuclear $M_{2}$.

(i) Intralayer Distances between Alkali Cations. In an alkali chain or layer the closest approach to other alkali cations is with those located in the same chain or layer. Cation chains have linear geometry, and therefore, any given cation will, in general, have two of every nearest interaction mirrored: roughly, in front and behind. Cation layers have planar geometry, and thus, there are four nearly identical interactions with its closest neighbors: in front, behind, and to either side. In most instances there is little variation of the closest approach distances among isochemical structures sharing the same topology, and most variation that is observed can be explained by bulk density.

(ii) Interlayer Distance between Alkali Cations. Structures where the alkali layers are close to each other will experience stronger homonuclear second moments than those structures where the layers are positioned further apart. A quick analysis of the structural diversity found within the $\mathrm{Na}_{2} \mathrm{Si}_{2} \mathrm{O}_{5}$ system 


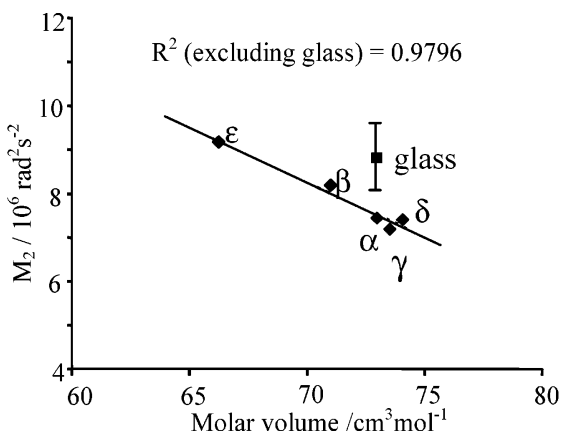

(a) $\mathrm{Na}_{2} \mathrm{O} \cdot 2 \mathrm{SiO}_{2}$

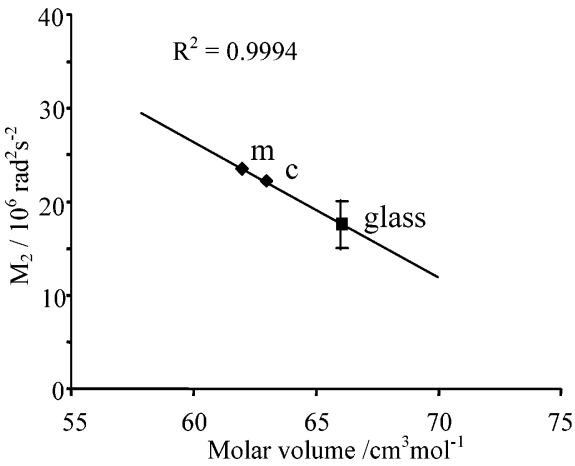

(b) $\mathrm{Li}_{2} \mathrm{O} \cdot 2 \mathrm{SiO}_{2}$

Figure 9. Comparison of the heteronuclear $M_{2}$ values with molar volume. A line of the best fit for each data set is shown along with the corresponding $R^{2}$ factor (the fit in Figure 9a excludes the glass data point).

exhibits the affect of a layer structure on the homonuclear $M_{2 \mathrm{E}}$. The ordering of the layers looking along the $c$ axis for four crystalline sodium disilicate phases is presented in Figure 8. Recall that Figure 7a shows the ${ }^{23} \mathrm{Na} M_{2 \mathrm{E}}$ as a function of molar volume for the $\mathrm{Na}_{2} \mathrm{Si}_{2} \mathrm{O}_{5}$ crystalline phases; the $\beta, \delta$, and $\epsilon$ phases show a very good linear correlation; however, the $\alpha$ phase has a lower $M_{2 \mathrm{E}}$ than the molar volume trend would predict. The $\mathrm{SiO}_{4}$ layer in this phase is structured differently than the other phases, possessing a more pronounced puckered texture. This structuring results in a very long $b$ axis and an increased distance between sodium layers. When the $M_{2 \mathrm{E}}$ is plotted as a function of the $b^{\prime}$ axis (the projection of the unit cell $b$ axis onto the normal of the $a c$ plane), as shown in Figure $7 \mathrm{~b}$, a linear correlation for all four phases is observed. This verifies that the divergence of the $\alpha M_{2 \mathrm{E}}$ from those of the $\beta$, $\delta$, and $\epsilon$ phases is directly related to the layered topology of its structure.

(iii) Interlayer Distances between the Silicate Structures and Alkali Cations. Structures with weaker interactions between the alkali and silicate layers will have weaker heteronuclear second moments than those materials where there is more of an overlap between layers or chains and alkali cations are fit into the grooves created by the corrugation of the $\mathrm{SiO}_{4}$ chains. Similar to the affect on the $M_{2 \mathrm{E}}$ of intralayer alkali distances, this affect is minor and largely a consequence of bulk density. The coordination of the alkali cations to bridging and nonbridging oxygen atoms is also thought to be of some importance.

Analysis of Second Moments Measured in Glass. Second moments measured for the sodium and lithium disilicate glasses are not directly comparable to each other and alone reveal essentially nothing about structure. Comparisons between the crystalline and amorphous phases, on the other hand, are at least partially valid if the materials have identical stoichiometry and molar volume is considered. Second-moment values and molar

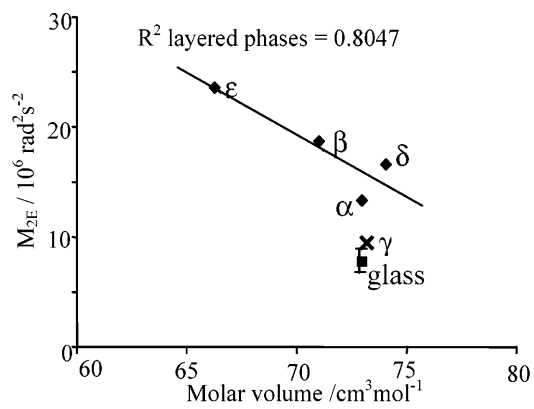

(a) $\mathrm{Na}_{2} \mathrm{O} \cdot 2 \mathrm{SiO}_{2}$

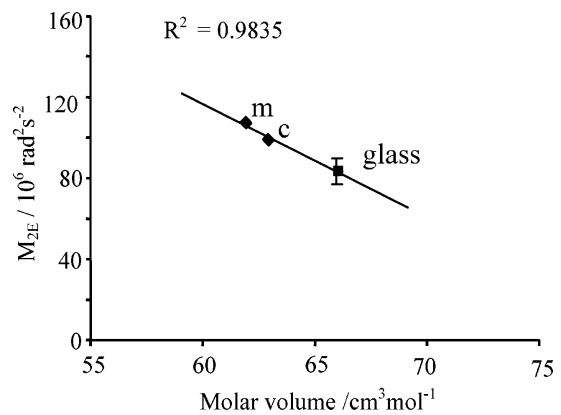

(b) $\mathrm{Li}_{2} \mathrm{O} \cdot 2 \mathrm{SiO}_{2}$

Figure 10. Comparison of the homonuclear $M_{2 \mathrm{E}}$ values with molar volume. A line of the best fit for each data set is shown along with the corresponding $R^{2}$ factor (the fit in Figure 10a excludes the glass and $\gamma$ data points).

volumes for each phase of the $\mathrm{Na}_{2} \mathrm{Si}_{2} \mathrm{O}_{5}$ and $\mathrm{Li}_{2} \mathrm{Si}_{2} \mathrm{O}_{5}$ systems are listed in Table 3.

Figure 9 a compares the measured ${ }^{29} \mathrm{Si}-{ }^{23} \mathrm{Na} \mathrm{M}$ of the N2S glass to those calculated from the structure for five crystalline $\mathrm{Na}_{2} \mathrm{Si}_{2} \mathrm{O}_{5}$ phases as a function of molar volume. For the layered phases there is a linear correlation between $M_{2}$ and molar volume with an $R^{2}$ value of 0.9796 . The second moment measured for the glass is slightly greater than the $M_{2} /$ molar volume trend observed for the crystalline phases predicts. A $t$-test for the glass comparing the actual measurement to the value predicted by the linear trend shows that there is a probability of less than $80 \%$ that the experimental value is statistically different from the layered phases when an experimental error of $\pm 10 \%$ is assumed. It is also observed using a $t$-test that although the $\gamma$ phase is not layered its $M_{2}$ agrees with those of the layered silicates with there being a probability of less than $50 \%$ that this value is statistically different. It is not unreasonable to suggest that qualitatively the value measured for the N2S glass agrees with those of the crystalline phases. However, REDOR measurements of $M_{2}$ are rarely overestimations; in general, there is a systematic bias for underestimations of $M_{2}$ resulting from $\pi$ pulse missets. Figure $9 \mathrm{~b}$ compares the measured ${ }^{29} \mathrm{Si}-{ }^{7} \mathrm{Li} \mathrm{M} \mathrm{M}_{2}$ of the L2S glass and those calculated for two crystalline $\mathrm{Li}_{2} \mathrm{Si}_{2} \mathrm{O}_{5}$ phases to the molar volume of each phase. The $M_{2}$ of the glass agrees exactly with those values for the limited set of crystalline phases, producing a linear fit with an $R^{2}$ value of 0.9994 .

The similarity of the crystalline silicate heteronuclear second moments regardless of topology as well as the observations that the L2S glass agrees exactly while the N2S glass is similar within error to the crystalline phases suggests that heteronuclear second moments are so dominated by density and composition that REDOR experiments are perhaps not sensitive enough to extract the subtle differences caused by slight structural variations. 


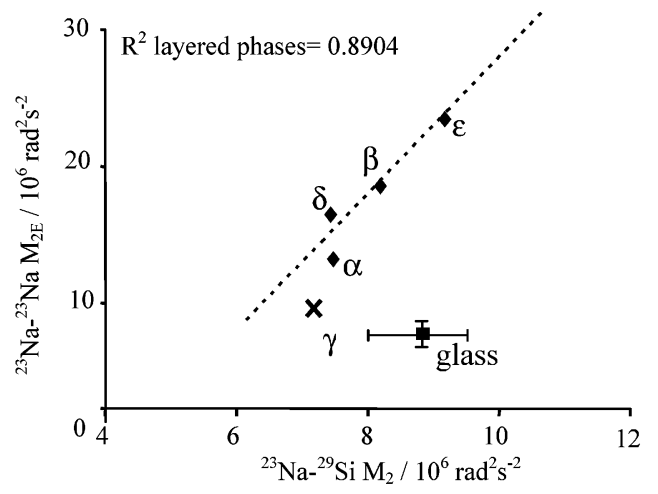

(a) $\mathrm{Na}_{2} \mathrm{O} \cdot 2 \mathrm{SiO}_{2}$

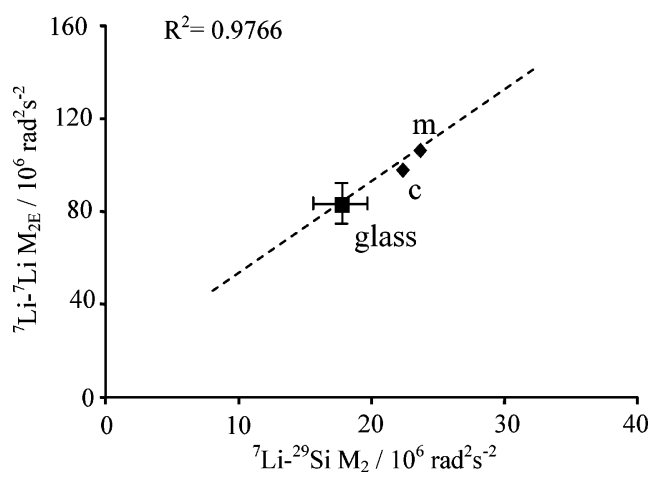

(b) $\mathrm{Li}_{2} \mathrm{O} \cdot 2 \mathrm{SiO}_{2}$

Figure 11. Comparison of the homonuclear $M_{2 \mathrm{E}}$ values with the heteronuclear $M_{2}$ values. A line of the best fit for each data set is shown along with the corresponding $R^{2}$ factor (the fit in Figure 11a excludes the glass and $\gamma$ data points).

Similar to the treatment for heteronuclear second moments, the homonuclear second moments measured for the glasses and those calculated from crystal structures are compared to the molar volume of each phase in Figure 10a for N2S and 10b for L2S. For the sodium disilicate system there is a reasonably good linear fit observed for the layered crystalline phases with an $R^{2}$ of 0.8047 . The goodness of the fit, however, is reduced by the $\alpha$ phase, which has an elongated $b$ axis as discussed above. The $\gamma$ phase was not included in the $R^{2}$ analysis because its nonlayered topology causes the $M_{2 \mathrm{E}}$ to deviate significantly from those of the layered silicates. The value measured for the glass diverges from those of the layered phases but is very similar to that of the $\gamma$ phase. A $t$-test shows that assuming an error of $\pm 10 \%$ there is greater than a $99 \%$ probability that the $M_{2 \mathrm{E}}$ values of both the glass and the $\gamma$ phase are statistically different from those predicted by the linear trend of the layered phases. For the lithium disilicate system there is a good linear correlation between $M_{2 \mathrm{E}}$ and the molar volume for both crystalline phases and the glass with an $R^{2}$ of 0.9835 . Overall, the $M_{2 \mathrm{E}}$ measured for the N2S glass is much lower than expected from its molar volume considering the trend observed for the layered phases, while the value measured for the L $2 \mathrm{~S}$ glass agrees exactly with the linear trend of the crystalline phases.

Figure 11a and $\mathrm{b}$ shows a more direct comparison of the glass and crystalline second moments by plotting the homonuclear $M_{2 \mathrm{E}}$ as a function of the heteronuclear $M_{2}$ for each system. For the sodium disilicate system there is a linear correlation among all of the layered crystalline phases with an $R^{2}$ value of 0.8904 . A $\chi^{2}$ analysis for independence of the glass data compares the experimentally determined second moments to those expected hypothetically from the linear trends of the layered phases. For the glass this analysis produces a $\chi^{2}$ probability of 0.035 , meaning that there is only a $3.5 \%$ chance that these values agree with the hypothetical model, which is below the classically accepted cutoff of 5\%, indicating that the data does not fit the model. A similar analysis of the $\gamma$ phase results in a $\chi^{2}$ probability of 0.146 , which is above the cutoff, meaning that it cannot be rejected outright that these second-moment values do not follow the same trend as the layered phases. The probability it is still quite low however, meaning that the trend of the layered phases is not followed particularly well. For the lithium disilicate system there is still a good linear correlation between the two crystalline phases and the glass, producing an $R^{2}$ value of 0.9766 .

The correlations observed for the L2S glass strongly suggest that the intermediate-range ordering in this glass is at least somewhat similar to that found in the crystalline phases. It is very likely that there is a high concentration of sheet-like silicate structures capable of layering and producing a topology essentially similar to that of the layered silicates. The lack of strong correlations for the $\mathrm{N} 2 \mathrm{~S}$ glass strongly suggest that the intermediate-range ordering of this glass is dissimilar to that of the layered crystalline phases. The ${ }^{23} \mathrm{Na} M_{2 \mathrm{E}}$ suggests that at least some similarity exists between the intermediate-range ordering of the N2S glass and the $\gamma$ phase. It is possible that the topology of the glass is similar to that of the $\gamma$ network.

\section{Conclusions}

Comparison of the measured ${ }^{29} \mathrm{Si} /{ }^{23} \mathrm{Na}$ or ${ }^{29} \mathrm{Si} /{ }^{7} \mathrm{Li}$ heteronuclear second moments of the N2S and L2S glasses with their isochemical crystalline phases as a function of the molar volume of each material reveals a linear correlation among each set of crystalline phases that was shared by the L2S glass but not the N2S glass. A similar result was observed when the ${ }^{23} \mathrm{Na}$ and ${ }^{7} \mathrm{Li}$ homonuclear second moments were analyzed in the same manner; however, $\gamma-\mathrm{Na}_{2} \mathrm{Si}_{2} \mathrm{O}_{5}$, which has a distinctly different topology, also does not follow the linear trend and instead agrees better with the value measured for the N2S glass. When the homonuclear second moment was compared directly to the heteronuclear second moment a linear correlation was again observed for the crystalline phases and again the L2S glass agreed with the trend while N2S glass diverged somewhat. While the second-moment measurements do not directly indicate intermediate-range order, the comparisons with isochemical structures strongly indicate that the L2S measurements are consistent with a crystalline-like intermediate-range order whereas the $\mathrm{N} 2 \mathrm{~S}$ measurements are not.

A topology is proposed for the L2S glass that consists mainly of medium-sized sheet-like structures capable of ordering themselves in layers. For the N2S glass a continuous 3D network similar to $\gamma-\mathrm{Na}_{2} \mathrm{Si}_{2} \mathrm{O}_{5}$ seems more probable. These observations and the proposed structures that arise from them support the initial hypothesis that the L2S glass, which undergoes homogeneous nucleation, is structurally very similar to its stable isochemical crystalline phases at the intermediate-range level whereas the N2S glass, which only undergoes heterogeneous nucleation, is not.

Acknowledgment. J.G.L. thanks NSERC for a CGSM scholarship. Funding from the Inter-American Materials Collaboration program of NSERC and CNPq-Brazil is gratefully acknowledged. Natalia Karpukhina is gratefully acknowledged for assistance with MQMAS.

\section{References and Notes}

(1) Maekawa, H.; Yokokawa, T. Geochim. Cosmochim. Acta 1997, $61,2569$. 

107,9

2) Kanzaki, M.; Xue, X.; Stebbins, J. F. Phys. Earth Planet. Int. 1998

(3) Nascimento, M. L. F.; Souza, L. A.; Ferreira, E. B.; Zanotto, E. D. J. Non-Cryst. Solids 2005, 351, 3296.

(4) Fokin, V. M.; Nascimento, M. L. F.; Zanotto, E. D. J. Non-Cryst. Solids 2005, 351, 789.

(5) Schneider, J.; Mastelaro, V. R.; Panepucci, H.; Zanotto, E. D. J. Non-Cryst. Solids 2000, 273, 8

(6) Hölland, W.; Beall, G. Glass-Ceramic Technology; The American Ceramic Society: Westerville, OH, 2002.

(7) Stookey, S.D. U.S. Patent 2,920,971, 1960.

(8) Dupree, R.; Holland, D.; Mortuza, M. G. J. Non-Cryst. Solids 1990 $116,148$.

(9) Souza, L. A.; Leite, M. L. G.; Zanotto, E. D.; Prado, M. O. J. NonCryst. Solids 2005, 351, 3579.

(10) Zanotto, E. D.; Müller, E. J. Non-Cryst. Solids 1991, 130, 220.

(11) Mastelaro, V. R.; Zanotto, E. D.; Lequeux, N.; Cortes, R. J. NonCryst. Solids 2000, 262, 191.

(12) Deubener, J. J. Non-Cryst. Solids 2003, 351, 1500.

(13) Elliott, S. R. Nature 1981, 294, 692.

(14) Zachariasen, W. H. J. Am. Chem. Soc. 1932, 54, 3841

(15) Selvaray, U.; Rao, K. J.; Rao, C. N. R.; Klinowski, J.; Thomas, J. M. Chem. Phys. Lett. 1985, 114, 24.

(16) Uhlig, H.; Hoffmann, M. J.; Lamparter, H.; Aldinger, F.; Bellissent, R.; Steeb, S. J. Am. Ceram. Soc. 1996, 79, 2839.

(17) Zhao, J.; Gaskell, P. H.; Cluckie, M. M.; Soper, A. K. J. NonCryst. Solids 1998, 232-234, 721.

(18) Huang, C.; Cormack, A. N. J. Chem. Phys. 1990, 93, 8180

(19) Uhlig, H.; Hoffmann, M. J.; Lamparter, H.; Aldinger, F.; Bellissent,

R.; Steeb, S. J. Am. Ceram. Soc. 1996, 79, 2833.

(20) Warren, B. E.; Loring, A. D. J. Am. Ceram. Soc. 1935, 18, 269.

(21) Maekawa, H.; Maekawa, T.; Kawamura, K.; Yokokawa, T. J. NonCryst. Solids 1991, 127, 53.

(22) Janes, N.; Oldfield, E. J. Am. Chem. Soc. 1985, 107, 6769.

(23) Emerson, J. F.; Stallworth, P. E.; Bray, P. J. J. Non-Cryst. Solids 1989, 113,253

(24) Stebbins, J. F. Nature 1987, 330, 465.

(25) Gaskell, P. H. J. Non-Cryst Solids 2005, 351, 1003

(26) Greaves, G. N.; Fontaine, A.; Lagarde, P.; Raoux, D.; Gurman, S. J. Nature 1981, 293, 611.

(27) Du, J.; Cormack, A. N. J. Non-Cryst. Solids 2004, 349, 66

(28) Meyer, A.; Horbach, J.; Kob, W.; Kargl, F.; Schober, H. Phys. Rev. Lett. 2004, 93, 027801.

(29) van Wüllen, L.; Eckert, H.; Schwering, G. Chem. Mater. 2000, 12,1840 .

(30) Strojek, W.; Kalwei, M.; Eckert, H. J. Chem. Phys. Chem. B 2004, 108,7061 .

(31) Strojek, W.; Eckert, H. Phys. Chem. Chem. Phys. 2006, 8, 2276.

(32) Zhang, L.; Eckert, H. J. Mater. Chem. 2005, 15, 1640.

(33) Zeyer-Düsterer, M.; Montagne, L.; Palvit, G.; Jäger, C. Solid State Nucl. Magn. Reson. 2005, 27, 50.

(34) Janssen, M.; Eckert, H. Solid State Ionics 2000, 136-137, 1007.

(35) van Wüllen, L.; Gee, B.; Züchner, L.; Bertmer, M.; Eckert, H. Ber. Bunsenges. Phys. Chem. 1996, 100, 1539.

(36) Gee, B.; Janssen, M.; Eckert, H. J. Non-Cryst. Solids 1997, 215 41.

(37) Voigt, U.; Lammert, H.; Eckert, H.; Heuer, A. Phys. Rev. B 2005 , $72,064207$.

(38) Ratai, E.; Janssen, M.; Eckert, H. Solid State Ionics 1998, 105, 25.

(39) Zwanziger, J. W.; McLaughlin, J. C.; Tagg, S. L. Phys. Rev. B 1997, 56, 5243 .
(40) Gee, B.; Eckert, H. Solid State Nucl. Magn. Reson. 1995, 5, 113

(41) Reynhardt, E. C. Can. J. Phys. 1989, 67, 592.

(42) van Vleck, J. H. Phys. Rev. 1948, 74, 1168

(43) Williamson, J.; Glasser, F. P. Phys. Chem. Glasses 1966, 7, 127.

(44) Willgallis, V. A.; Range, K. J. Glastechn. Ber. 1964, 37, 194.

(45) Soares, P. C., Jr.; Zanotto, E. D.; Fokin, V. M.; Jain, H. J. NonCryst. Solids 2003, 331, 217.

(46) Garbow, J. R.; Gullion, T. J. Magn. Reson. 1991, 95, 442.

(47) Gullion, T.; Baker, D. B.; Conradi, M. S. J. Magn. Reson. 1990 $89,479$.

(48) Mortuza, M. G.; Dupree, R.; Holland, D. J. Mater. Sci. 2000, 35 2829.

(49) Trill, H.; Eckert, H.; Sradnov, V. I. J. Phys. Chem. B 2003, 107, 8779 .

(50) Bertmer, M.; Eckert, H. Solid State Nucl. Magn. Reson. 1999, 15, 139.

(51) Epping, J. D.; Strojek, W.; Eckert, H. Phys. Chem. Chem. Phys. 2005, 7, 2384 .

(52) Louie, E. A.; Chirakul, P.; Raghunathan, V.; Sigurdsson, S. T.; Drobny, G. P. J. Magn. Reson. 2005, 178, 11

(53) Hesse, K. F. Acta Crystallogr. 1977, 33B, 901

(54) Hassan, I.; Grundy, H. D. Acta Crystallogr. 1984, B40, 6.

(55) Pant, A. K.; Cruickshank, D. W. J. Acta Crystallogr. 1968, B24,

(56) Zalkin, A.; Forrester, J. D.; Templeton, D. H. Acta Crystallogr 1964, 17, 1408 .

(57) Horbach, J.; Kob, W.; Binder, K. Phys. Rev. Lett. 2002, 88, 125502.

(58) Jund, P.; Jund; Kob, W.; Jullien, R. Phys. Rev. B 2001, 64, 134303.

(59) Haase, J.; Oldfield, E. J. Magn. Reson. A 1993, 101, 30.

(60) Alam, T. M.; Mclaughlin, J.; Click, C. C.; Conzone, S.; Brew, R. K.; Boyle, T. J.; Zwanziger, J. W. J. Phys. Chem. B 2000, 104, 1464.

(61) Puls, S. P.; Eckert, H. Phys. Chem. Chem. Phys. 2007, 9, 3992.

(62) Macdonald, W. S.; Cruickshank, D. W. J. Acta Crystallogr. 1967, $22,37$.

(63) Nord, A. G. Acta Chem. Scand. 1973, 27, 814.

(64) Du, J.; Corrales, L. R. J. Chem. Phys. 2006, 125, 114702.

(65) Smith, W.; Greaves, G. N.; Gillan, M. J. J. Chem. Phys. 1995, 103,3091

(66) De Jong, B. H. W. S.; Super, H. T. J.; Spek, A. L.; Vledman, N.; Nachtegaal, G.; Fischer, J. C. Acta Crystallogr. 1998, B54, 568.

(67) Smith, R. I.; Howie, R. A.; West, A. R. Acta Crystallogr. 1990, C46, 135 .

(68) Heidemann, D.; Hübert, C.; Schwieger, W.; Grabner, P.; Bergk, K.; Sarv, P. Z. Anorg. Alleg. Chem. 1992, 617, 169.

(69) Pant, A. K. Acta Crystallogr. 1968, B24, 1077.

(70) Kahlenberg, V.; Dörsam, G.; Wendschih-Josties, M.; Fischer, R. X. J. Solid State Chem. 1999, 146, 380.

(71) Hoffman, V. W.; Scheel, H. Z. Kristallogr. 1969, 129, 396.

(72) Fleet, M. E.; Henderson, G. S. J. Solid State Chem. 1995, 119, 400 .

(73) Kahlenberg, V.; Rakic, S.; Weidenthaler, C. Z. Kristallogr. 2003, $218,421$.

(74) Longstaffe, J. G. M.Sc. Thesis, Dalhousie University, Halifax, Nova Scotia, Canada, 2007.

(75) Klein, C.; Hurlbut, C.S., Jr. Manual of Mineralogy, 21st ed.; John Wiley \& Sons, Inc.: New York, 1993.

(76) Handbook of glass data; Mazurin, O. V., Strelstina, M. V., ShvaikoShvaikovskaya, T. P., Eds.; Elsevier: Amsterdam, 1983. 